\title{
Estimation of Percentage of Body Fat in Field Studies - A Method Based on Relative Elbow Breadth (Frame Index) and BMI
}

\author{
Rebekka Mumm¹ (ㄱ • Anna Reimann ${ }^{1}$ Christiane Scheffler ${ }^{1}$ () \\ ${ }^{1}$ University of Potsdam, Institute of Biochemistry and Biology, Human Biology, Potsdam, Germany.
}

\section{Citation:}

Mumm, R, Reimann, A, Scheffler, C (2021), Estimation of Percentage of Body Fat in Field Studies, Human Biology and Public Health 1. https://doi.org/10.52905/hbph.v1.3.

Received: 2020-08-24

Accepted: 2020-10-29

Published: 2021-06-22

\section{Copyright:}

This is an open access article distributed under the terms of the Creative Commons Attribution License which permits unrestricted use, distribution, and reproduction in any medium, provided the original author and source are credited.

Conflict of Interest:

There are no conflicts of interest.

Correspondence to:

Rebekka Mumm

email: rebekka.mumm@gmail.com

\section{Keywords:}

body fat estimator, body composition, skeletal robusticity, hidden obesity, normal weight obese

\begin{abstract}
Background Over the last 20 years, a decreasing trend in external skeletal robusticity and an increasing trend in overweight and obesity was observed worldwide in adults and children as modern lifestyles in nutritional and activity behavior have changed. However, body mass index (BMI) as a measure for overweight is not an ideal predictor of $\%$ body fat (\%BF) either in children and adolescents or in adults. On the contrary, it disguises a phenomenon called "hidden obesity".
\end{abstract}

Objectives We aim to approximate \%BF by combining skeletal robusticity and BMI and develop an estimation-based tool to identify normal weight obese children and adolescents.

Sample and Methods We analyzed cross-sectional data on height, weight, elbow breadth, and skinfold thickness (triceps and subscapular) of German children aged 6 to 18 years $(\mathrm{N}=15,034)$. We used modified Hattori charts and multiple linear regression to develop a tool, the "\%BF estimator", to estimate \%BF by using BMI and skeletal robusticity measured as Frame Index.

Results Independent of sex and age an increase in BMI is associated with an increase in \%BF, an increase in Frame Index is associated with a decrease in \%BF. The developed tool "\% BF estimator" allows the estimation of \%BF per sex and age group after calculation of BMI and Frame Index.

Conclusion The "\%BF estimator" is an easily applicable tool for the estimation of \% $\mathrm{BF}$ in respect of body composition for clinical practice, screening, and public health research. It is non-invasive and has high accuracy. Further, it allows the identification of normal weight obese children and adolescents.

Take home message for students For the estimation of \% body fat of children and adolescents with "\%BF estimator" in clinical practice, screening, and public health research height, weight and elbow breadth need to be collected. 


\section{Introduction}

Over the last 20 years, a decreasing trend in external skeletal robusticity was observed worldwide e.g., Germany, Russia, and Argentina (Hermanussen et al. 2015; Navazo et al. 2020; Rietsch et al. 2013b; Scheffler and Hermanussen 2014). The phenomenon is independent of sex and age and occurs not only in persons with average values but also in all centiles (Mumm et al. 2018; Navazo et al. 2020; Rietsch et al. $2013 b)$. For example, the $10^{\text {th }}$ centile of German boys of skeletal robusticity, measured by Frame Index (Frisancho 1990) in 2010 , is below the $3^{\text {rd }}$ centile of a similar cohort measured in 2000 (Rietsch et al. 2013a; Scheffler 2010). Similar results were found in Argentina (Navazo et al. 2020). In the short period of ten years a tremendous decline in skeletal robustness, independently of ethnicity, age and sex occurred worldwide mainly due to a lack of physical activity (Rietsch et al. 2013a).

Contemporaneously, the world is experiencing a global epidemic of overweight and obesity in adults and children as modern lifestyles in nutritional and activity behavior have changed. In 1975, 5 million girls and 6 million boys globally were classified as obese (individual body mass index (BMI) 2 BMI SDS of reference). Nowadays, 30 years later, globally 50 million girls and 74 million boys are obese (NCD Risk Factor Collaboration 2017). The problem is still ongoing as changes in lifestyle, policies and environmental conditions are very slow (Swinburn et al. 2019). Recently, adults with a BMI within the normal range but a high amount body fat (BF) were described and defined as "normal weight obese" (NWO) (Lorenzo et al. 2006; Marques-Vidal et al. 2010; Mokhtar et al. 2001; Romero-Corral et al. 2010). The phenomenon is also known as "hidden obesity" (Mokhtar et al. 2001). The definition also applies to children that have a highfat mass and low-fat free mass but their $\mathrm{BMI}$ is within a normal range (Czernitzki et al. 2017; Wohlfahrt-Veje et al. 2014), however, commonly agreed cut-offs for the percentage of $\mathrm{BF}(\% \mathrm{BF})$ to define overweight and obesity in children are still missing (Czernitzki et al. 2017; WohlfahrtVeje et al. 2014).

Skeletal robusticity, body mass, and body composition interact e.g., an increase in skeletal dimensions is associated with an increase in BF (La Guzmán-de Garza et al. 2017). The interaction was described in detail by Rietsch et al. (2013a). They propose a triangular interaction that is mediated by physical activity. BMI, \%BF, and Frame Index are positively correlated with each other. Thereby, \%BF and Frame Index have a direct positive influence on BMI. Further, due to the mediation an increase in physical activity increases the Frame Index but decreases BMI and \%BF. Additionally, physical activity acts as a mediator via Frame Index on BMI. An increase in physical activity increases Frame Index which effects BMI (Figure 1).

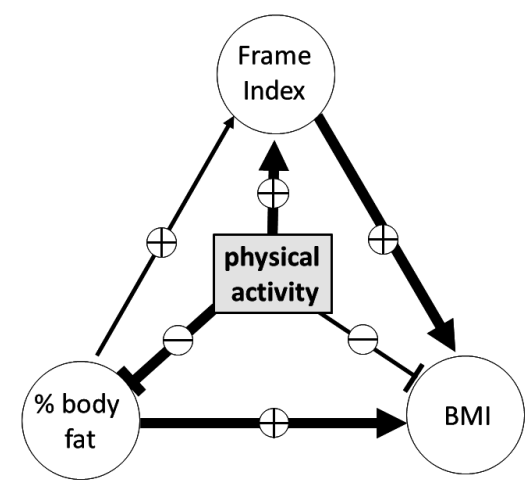

Figure 1 Interaction of BMI, Frame Index, \% body fat and physical activity (adapted after (Rietsch et al. 2013a; Scheffler and Hermanussen 2018)

As described earlier, BMI is used to identify overweight and obese children as BMI and $\% \mathrm{BF}$ are positively correlated. In general, boys and girls with a high BMI have 
a high amount of BF whereas the interaction is stronger in girls than in boys ( $\mathrm{La}$ Guzmán-de Garza et al. 2017; Prentice and Jebb 2001; Woolcott and Bergman 2019). Despite the high correlation, BMI is not an ideal predictor of \%BF either in children and adolescents or in adults (DeurenbergYap et al. 2000; Wells 2018; Wickramasinghe 2012). The relationship further depends on ethnicity as, for example, Asians have a lower BMI but at the same time a higher \%BF (Deurenberg-Yap et al. 2000; Prentice and Jebb 2001), however, bone measures do not differ significantly between ethnicities (Hetherington-Rauth et al. 2018). Although "bone mass, skeletal muscle mass, and fat mass are highly correlated with BMI" (Wells 2014), BMI is only a measure of height and weight and not body composition. It does not reflect population-specific body composition and is said to be a poor indicator of adiposity within and across populations (Wells 2014; 2018).

Reliable information on body composition and \%BF is obtained by dual-energy $\mathrm{X}$-ray absorptiometry (DXA), bio impendence analysis (BIA), or hydrostatic weighing (Borga et al. 2018). These methods are expensive, invasive (in case of DXA), and too demanding of equipment and effort (e.g., BIA) for low-cost fieldwork in e.g., kindergartens and schools. A valid substitute for public health research is the non-invasive measurement of skinfold thickness (Wells 2014) to calculate \%BF using the equation provided e.g., by Slaughter et al. (1988). However, skinfold thicknesses are rarely measured in screening programs, mostly in programs with a specialized research question, as a special caliper and training are needed for accurate measurements. Therefore, we aim to develop an easily applicable tool with high accuracy to estimate \%BF using standard measures of screening like height and weight and the measure of elbow breadth which has a low measure- ment error and requires almost no special training. Using BMI and skeletal properties might allow to combine information on fat mass and lean mass to estimate \% $\mathrm{BF}$ and might further allow identification of NWO children and adolescents (= children and adolescents with hidden obesity).

We hypothesize:

1. Frame Index and BMI together approximate \%BF in German boys and girls.

2. Relative low Frame Index and normal BMI is a proxy for hidden obesity in children and adolescents.

\section{Samples and Methods}

\section{Samples}

We analyzed cross-sectional data on height, weight, bi-epicondylar humerus, and skinfold thickness (triceps and subscapular) of German children aged 6 to 18 years. After Frisancho (1990), we refer to bi-epicondylar humerus as elbow breadth. Data originate from the baseline KIGGS-study (German Health Interview and Examination Survey for Children and Adolescents), a representative cross-sectional study conducted from 2003-2006. Details of the study can be found elsewhere (Hölling et al. 2012; Kamtsiuris et al. 2007). Additionally, data of several different studies of children and adolescents from Berlin and the federal state of Brandenburg were used. For details see Schilitz (2001), Schüler (2009), Rietsch et al. (2013a). Due to data aggregation, 15,034 children and adolescents were analyzed altogether. Table 1 shows the sample sizes per sex and age group.

\section{Methods}

As an indicator of the external skeletal robusticity, the Frame Index was used. It was 
Table 1 Sample size per sex and age group

\begin{tabular}{|cccccccccccccccc|}
\hline age & 6 & 7 & 8 & 9 & 10 & 11 & 12 & 13 & 14 & 15 & 16 & 17 & 18 & total \\
\hline girls & 736 & 706 & 719 & 772 & 694 & 659 & 588 & 512 & 488 & 502 & 451 & 505 & 93 & 7425 \\
\hline boys & 828 & 739 & 667 & 779 & 735 & 668 & 604 & 565 & 523 & 531 & 456 & 457 & 57 & 7609 \\
\hline total & 1564 & 1445 & 1386 & 1551 & 1429 & 1327 & 1192 & 1077 & 1011 & 1033 & 907 & 962 & 150 & 15034 \\
\hline
\end{tabular}

calculated after Frisancho (1990): Frame Index $=$ elbow breadth (in $\mathrm{mm}$ )/height (in $\mathrm{cm})^{*} 100$. The interobserver technical error of measurement (TEM) for elbow breadth is $1.54 \mathrm{~mm}$ (Frisancho 1990). Further, we calculated BMI as the quotient of weight (in $\mathrm{kg}$ ) and squared height (in $\mathrm{m}$ ). For the estimation of $\% \mathrm{BF}$, equations based on skinfold thickness (triceps and subscapular), published by Slaughter et al. (1988) were used. Interobserver TEM for skinfolds at triceps and subscapular is $1.06 \mathrm{~mm}$ and $2.28 \mathrm{~mm}$ respectively (Ulijaszek and Lourie 1994). Estimation of \%BF by Frisancho (1990) has a standard error of the estimate (SEE) of 3-4\%. Modified body proportion charts as proposed by Hattori et al. (2011; 1997) were applied to the dataset to visualize the relationship of \%BF, Frame Index, and BMI. Frame Index was presented on the $\mathrm{x}$-axis, BMI on the $\mathrm{y}$-axis, and \%BF was added as splines (see Figure 2 and 3). To estimate $\% \mathrm{BF}$ depending on Frame Index and BMI, we conducted linear regression models for each sex and age group as \% BF varies between sexes and changes with development and maturation of children and adolescents (Wells 2018). Age groups were defined as completed years (age group 6: 6.00 to 6.99 years). Children and adolescents with a BMI under the $90^{\text {th }}$ centile and $\mathrm{a} \% \mathrm{BF}$ above the $85^{\text {th }}$ centile of appropriate references were classified as normal weight obese ( $=$ hidden obese) adapting a definition by Czernitzki et al. (2017).

\section{Results}

The estimated \%BF per sex and age group by Frame Index and BMI are presented as modified Hattori chart in Figure 2 and 3. These charts act as a tool to estimate $\% \mathrm{BF}$ and are therefore called "\%BF estimator". Independent of sex and age a positive interaction of $\mathrm{BMI}$ and \% $\mathrm{BF}$ and a negative association of Frame Index and \%BF can be overserved. An increase in BMI is associated with an increase in \%BF, an increase in Frame Index is associated with a decrease in \%BF. Exceptional, 11- and 12year-old girls show a slightly reverse association. The presented figures are references for the estimation of $\% \mathrm{BF}$, detailed figures per sex and age group are presented in the supplementary files S1 and S2. To use the references BMI and Frame Index need to be calculated and added to the reference graph before \%BF can be extracted.

Specific examples for 8-year-old girls are presented in Figure 4. For all example patients, the following references were used: Mumm et al. (2018) for Frame Index and Schaffrath et al. (2010) for BMI. Children with a BMI above the $90^{\text {th }}$ centile of a specific reference are classified as overweight (after recommendations by Kromeyer-Hauschild et al. (2001)). The children differ in centiles (C) of Frame Index and BMI:

- Child 1 (P1): Frame Index C10 (10 ${ }^{\text {th }}$ centile) and BMI C10

- Child 2 (P2): Frame Index C10 and BMI C90

- Child 3 (P3): Frame Index C50 and BMI C50 

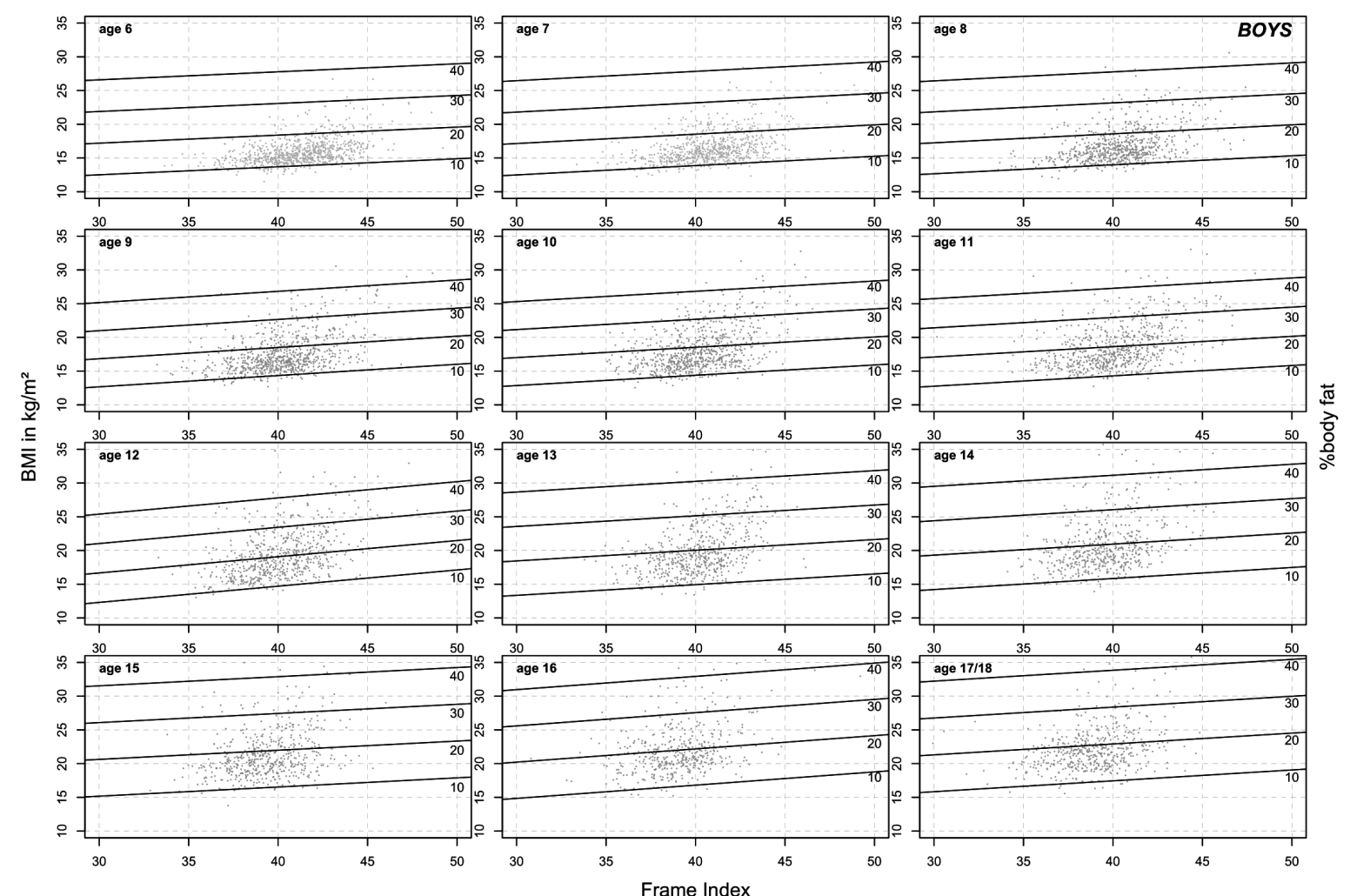

Figure 2 References for the estimation of \%body fat by Frame Index and BMl per age for boys ("\%BF estimator")

- Child 4 (P4): Frame Index C90 and BMI C10

- Child 5 (P5): Frame Index C25 and BMI C87

Child 5 is a real existing child not included in the dataset that was used for developing the "\%BF estimator". Child 5 further has a $\% \mathrm{BF}$ above the $85^{\text {th }}$ centile of German references of \%BF (dashed line) after Schwandt et al. (2012). Child 5 would not be classified as overweight as the BMI is below the $90^{\text {th }}$ centile but according to our definition child 5 would be classified as normal weight obese. Child 5 has an estimated \%BF of about $22.5 \%$. The measured $\% \mathrm{BF}$ of child 5 is $22.2 \%$. Similar examples (not shown) can be found in boys and girls of all ages.

\section{Discussion}

In this paper, we developed an easily applicable tool, the "\%BF estimator" to approximate \%BF by Frame Index and BMI in German boys and girls. Hence, our first hypothesis is true. The "\%BF estimator" has implications for clinical practice and public health research as with the tool it is easily possible to estimate \% $\mathrm{BF}$ without complex equations and calculations for the user by using the standard indexes BMI and Frame Index. "\%BF estimator" could, therefore, be used in all kinds of settings, particularly in low budget studies, for population-wide screening, etc. in high-, low- and middleincome countries, but also in screening programs in well-developed countries. Additionally, our second hypothesis is true as well. "\%BF estimator" can be used to identify NWO children and adolescents as seen in example child 5 in Figure 4. Child 

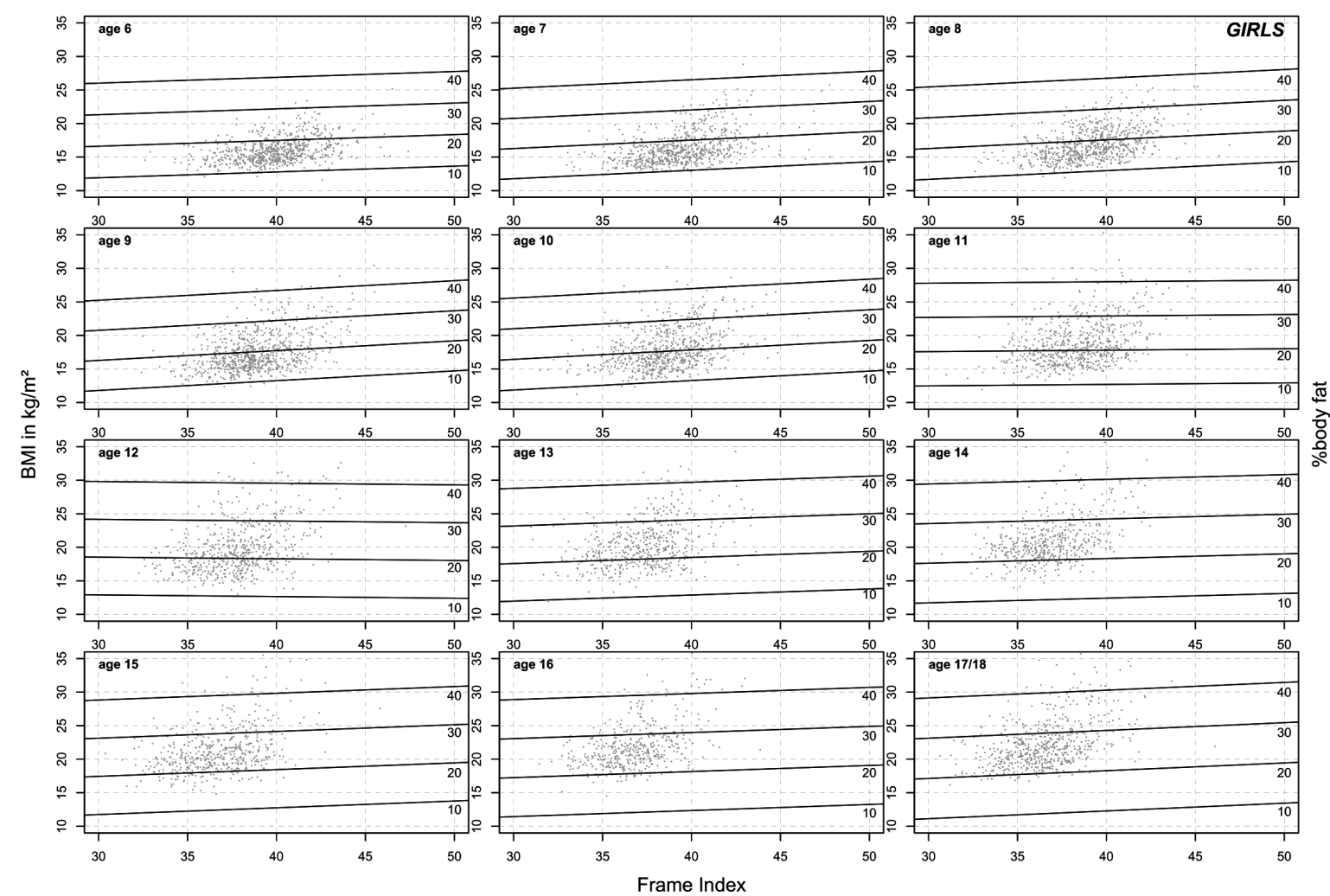

Figure 3 References for the estimation of \%body fat by Frame Index and BMl per age for girls ("\%BF estimator")

5 is classified as NWO by an adaption of Czernitzki et al. (2017). The girl has a BMI within a normal range (between $10^{\text {th }}$ and $90^{\text {th }}$ centile) and a $\% \mathrm{BF}$ above the $85^{\text {th }}$ centile. As seen in Figure 4, the girl's Frame Index is very low $\left(10^{\text {th }}\right.$ centile, $\left.\mathrm{C} 10\right)$. This is in line with results published by Musálek et al. (2018). They found NWO children to have the lowest values of Frame Index. Children and adolescents with a normal BMI but low skeletal robusticity measured by Frame Index are at risk of suffering from hidden obesity.

It is known that adults classified as NWO have a higher risk of cardiovascular and metabolic diseases (Lorenzo et al. 2006; Marques-Vidal et al. 2010; Romero-Corral et al. 2010). "Similar risk patterns may apply to children at school age with \%BF above the upper limit" (Wohlfahrt-Veje et al. 2014). Therefore, it is important to identify NWO boys and girls with easily ap- plicable tools. The "\%BF estimator" seems to be such a tool but further research is necessary to evaluate the tool in other populations and on children that are classified as NWO by other measures e.g., DXA. NWO children and adolescents are often not focused on when screening the population on overweight and obesity or in daily clinical practice. As NWO boys and girls have "normal" BMI, they do not appear overweight or obese although their risk for cardiovascular and metabolic diseases might be the same. If integrated into standard screening procedures and guidelines for pediatricians the "\%BF estimator" can help to identify children at risk. NWO children, adolescents and adults are often also referred to as "skinny fat". The opposites of NWO is called "healthy obese" people with BMI that classifies them as overweight, but a \%BF within the normal 


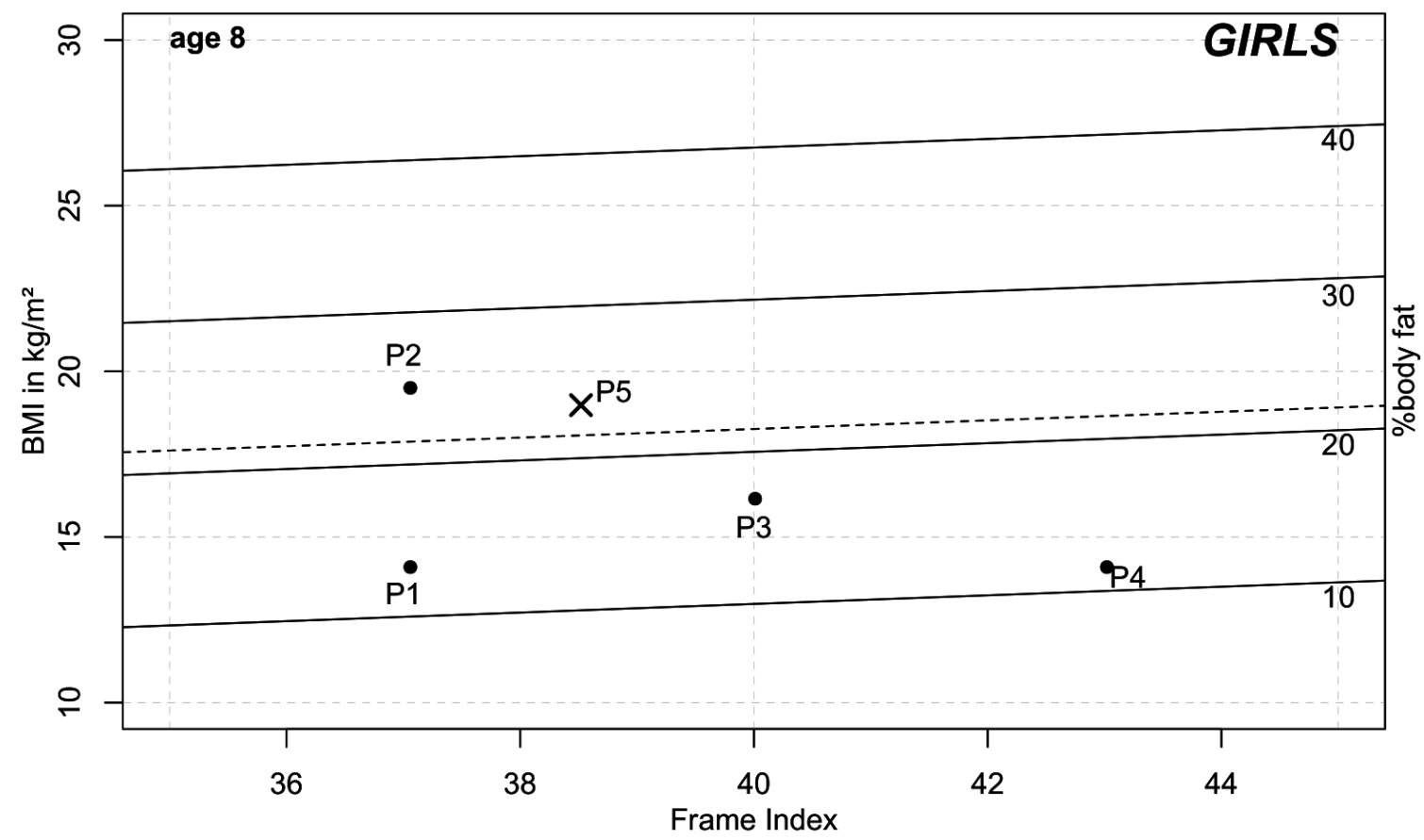

Figure 4 Examples \%body fat estimation of 8-year old girls differing in BMI and Frame Index $\left(P_{n}-\right.$ child $\left.{ }_{n}\right) .85^{\text {th }}$ centile of German \% body fat references (Schwandt et al. 2012) added as a dashed line.

range. A phenomenon often seen in sportsmen e.g., body builders.

But what are the advantages of the "\%BF estimator"? As commonly known, BMI alone is a poor predictor for \%BF. Wickramasinghe (2012) found an increase in fat mass but not in lean mass when body weight increases in Sri Lankan children and assumed a lack of physical activity to be the underlying cause. Similar conclusions were drawn by Rietsch et al. (2013b) for children in Germany and Russia. They use the Frame Index as a measure of skeletal robusticity and substitute for lean mass and showed a direct effect of physical activity on skeletal properties. The interaction of bone and body mass is more complex than generally assumed and "unlikely to be driven principally by the loading imparted by body mass due to gravity" (Pomeroy et al. 2018). Although fat mass is a component of body mass and contributes to skeletal loading, lean mass is the main determinant of limb bone strength, particularly on upper limbs (Hetherington-Rauth et al. 2018; Pomeroy et al. 2018). Skeletal properties can be used to estimate lean mass but they are not reliable for estimating fat mass (Pomeroy et al. 2018). Therefore, a combination of skeletal measures and BMI should be used to approximate \%BF like in the developed tool "\%BF estimator". The method behind "\%BF estimator" can be adapted to other populations with a different interaction of \% BF and BMI e.g., in Asia (Deurenberg-Yap et al. 2000; Prentice and Jebb 2001) by repeating the calculations using population-specific information on BMI and Frame Index.

Normal weight obese children have low skeletal robusticity probably due to a lack of physical activity. As seen in overweight 
children a reduction in BMI can be caused by a reduction of energy intake but not with an increased amount of physical activity (Birch et al. 2019). The success of physical activity in the reduction of overweight has to be measured differently (Epstein et al. 2008). Furthermore, although BMI is correlated with \%BF the "optimal percentile cutoff to define obesity in children differs between those with high muscle mass or a large body frame" (La Guzmán-de Garza et al. 2017). The interaction of lean mass and physical activity is not captured by BMI measurements and Frame Index seems to be a more appropriate measure (Rietsch et al. 2013a). We assume that an increase in Frame Index due to an increase in BMI is caused by an increase in body weight but not by higher levels of physical activity. Bones and skeletal muscles form a functional unit. "Fat mass is not a strong predictor of bone size or geometry" (Pomeroy et al. 2018), however, lean mass is. Lean mass contributes to all bones in strength and measurements, whereas fat mass only contributes to weight-bearing bones. Non-weight bearing bones like the upper limbs are not directly affected by fat mass, however, during bipedal locomotion muscles and bones in arms and shoulders interact (Preuschoft 2004). When walking the non-weight bearing bones of the upper limbs are moved due to pendulousness of shoulder and arms by muscles (Preuschoft 2004; Scheffler and Hermanussen 2014). As lean mass influences bone strength, physical activity like walking and thereby moving upper limbs, increase the Frame Index (Rietsch et al. 2013a; Scheffler and Hermanussen 2014). "Moreover, in the non-weight bearing diaphyseal radius, fat mass had a significant negative association with cortical bone content [...] and thickness [...]" (Hetherington-Rauth et al. 2018). Further research is needed to understand the proximate and ultimate causes of this interaction. However, Frame Index can be used as a substitute for lean mass and physical activity as it is measured on non-weight bearing bones. In combination BMI, which roughly measures the fat mass, the body composition of an individual can be taken into account.

Our published tool "\%BF estimator" is an easy tool to estimate \% $\mathrm{BF}$ in respect to individual body composition that is lowcost, non-invasive, and has high accuracy in terms of technical measurement errors for measurements of height, weight and elbow breadth. Height and weight are standard measurements in all screening programs globally and elbow breadth is a very easy measurement that requires almost no training usable by health care workers or researchers to integrate into said screening programs. Although bone measures are not population-specific the references used for "\%BF estimator" depend on age, sex, and population (Deurenberg-Yap et al. 2000; Hetherington-Rauth et al. 2018). Our developed tool might also be an answer to the statement of Pomeroy et al. (2018): "The ability to estimate fat and lean mass from skeletal characteristics would offer novel potential to investigate past human adaptation, health, and evolution, as well as to understand the origins of contemporary variation in body composition."

We recommend using the "\%BF estimator" in the field to approximate \%BF if other methods like DXA are not appropriate due to their invasive X-rays. Furthermore, the "\%BF estimator" can be used for the detection of NWO boys and girls in clinical practice and public health research. It is not practical to use in adults, because physical activity (correspondingly also the muscle mass and fat mass) can change over time, whereas the bone dimensions change only marginally in adults. In that case for adults the handgrip strength as an recent measure of muscular load at the same value of BMI is a good indicator of percentage of fat (Nickerson et al. 2020). 


\section{Limitations}

Our study is limited by several factors. First, \%BF data measured by DXA or hydrostatic weighing is missing. Second, as we used the equation by Slaughter et al. (1988) to calculated the \%BF for our analysis, we had to estimate the pubertal status in boys by age as recommended by Schwandt et al. (2012). However, a comparison of using Tanner stages (Tanner 1962) for classification of maturation or the age groups of Schwandt et al. (2012) showed no differences between the methods for the accuracy of \%BF calculation (Mumm 2015). Third, direct data on physical activity levels of children e.g., accelerometer data or questionnaires are missing, however, Frame Index and physical activity are positively correlated (Rietsch et al. 2013a). The analysis and estimation of the "\%BF estimator" tool could be repeated with data from DXA and accelerometry and differences in the methods could be compared by using the Bland-Altman approach (Bland and Altman 1986; 1999). Fourth, our tool was developed for the German population. As the relationship between BMI and \%BF slightly differs between ethnicities (Deurenberg-Yap et al. 2000), populationspecific adaptions are needed. The analyses can easily be repeated with data from other populations and population specific \%BF estimator plots can be created. Fifth, even within a country, several references for $\% \mathrm{BF}$ exist that are significantly different e.g., \%BF in Germany by Schwandt et al. (2012) or Plachta-Danielzik et al. (2012). Results of classifications might vary depending on the used references as cutoff values differ.

\section{Conclusion}

The "\%BF estimator" is an easily applicable tool for the estimation of \% $\mathrm{BF}$ in respect to body composition for clinical practice, screening, and public health research. It is non-invasive and the measurements have high accuracy. Further, it allows the identification of normal weight obese children. We recommend to integrate the measurement of elbow breadth into growth studies and population-wide screening to calculate \%BF and identify boys and girls at risk of hidden obesity.

\section{Contribution of Authors}

RM and CS designed the study. RM and AR analyzed the data. RM wrote the draft of the manuscript. All authors discussed the results and revised the manuscript.

\section{References}

Birch, L./Perry, R./Hunt, L. P./Matson, R./Chong, A./Beynon, R./Shield, J. P. (2019). What change in body mass index is associated with improvement in percentage body fat in childhood obesity? A meta-regression. BMJ open 9 (8), e028231. https://doi.org/10.1136/ bmjopen-2018-028231.

Bland, J. M./Altman, D. G. (1986). Statistical methods for assessing agreement between two methods of clinical measurement. The Lancet 1 (8476), 307-310. https://doi. org/10.1016/s0140-6736(86)90837-8.

Bland, J. M./Altman, D. G. (1999). Measuring agreement in method comparison studies. Statistical methods in medical research 8 (2), 135-160. https://doi.org/10.1177/096228029900800204.

Borga, M./West, J./Bell, J. D./Harvey, N. C./Romu, T./Heymsfield, S. B./Dahlqvist Leinhard, O. (2018). Advanced body composition assessment: from body mass index to body composition profiling. Journal of investigative medicine : the official publication of the American Federation for Clinical Research 66 (5), 1-9. https://doi. org/10.1136/jim-2018-000722. 
Czernitzki, A.-F./Kokstejn, J./Koziel, S./Mumm, R./Musalek, M./Papez, P./Scheffler, C. (2017). Impact of normal weight obesity on fundamental motor skills in pre-school children aged 3 to 6 years. Anthropologischer Anzeiger 74 (3), 203-212. https://doi.org/10.1127/anthranz/2017/0752.

Deurenberg-Yap, M./Schmidt, G./van Staveren, W. A./Deurenberg, P. (2000). The paradox of low body mass index and high body fat percentage among Chinese, Malays and Indians in Singapore. International Journal of Obesity and Related Metabolic Disorders : Journal of the International Association for the Study of Obesity 24 (8), 1011-1017. https://doi.org/10.1038/sj.ijo.0801353.

Epstein, L. H./Roemmich, J. N./Robinson, J. L./Paluch, R. A./Winiewicz, D. D./Fuerch, J. H./Robinson, T. N. (2008). A randomized trial of the effects of reducing television viewing and computer use on body mass index in young children. Archives of Pediatrics \& Adolescent Medicine 162 (3), 239-245. https://doi.org/10.1001/archpediatrics.2007.45.

Frisancho, A. R. (1990). Anthropometric standards for the assessment of growth and nutritional status. Ann Arbor, The Univ. of Michigan Pr.

Hattori, K./Hirohara, T./Satake, T. (2011). Body proportion chart for evaluating changes in stature, sitting height and leg length in children and adolescents. Annals of Human Biology 38 (5), 556-560. https://doi.org/10.3109/03014460.2011.577456.

Hattori, K./Tatsumi, N./Tanaka, S. (1997). Assessment of body composition by using a new chart method. American Journal of Human Biology 9 (5), 573-578. https:// doi.org/10.1002/(SICI)1520-6300(1997)9:5<573::AIDAJHB5 > 3.0.CO;2-V.

Hermanussen, M./Scheffler, C./Groth, D./Aßmann, C. (2015). Height and skeletal morphology in relation to modern life style. Journal of Physiological Anthropology 34, 41. https://doi.org/10.1186/s40101-015-0080-4.

Hetherington-Rauth, M./Bea, J. W./Blew, R. M./Funk, J. L./Hingle, M. D./Lee, V. R./Roe, D. J./Wheeler, M. D./Lohman, T. G./Going, S. B. (2018). Relative contributions of lean and fat mass to bone strength in young Hispanic and non-Hispanic girls. Bone 113, 144-150. https://doi.org/10.1016/j.bone.2018.05.023.

Hölling, H./Schlack, R./Kamtsiuris, P./Butschalowsky, H./Schlaud, M./Kurth, B. M. (2012). Die KiGGSStudie. Bundesweit repräsentative Längs- und Querschnittstudie zur Gesundheit von Kindern und Jugendlichen im Rahmen des Gesundheitsmonitorings am Robert Koch-Institut [The KiGGS study. Nationwide representative longitudinal and cross-sectional study on the health of children and adolescents within the framework of health monitoring at the Robert Koch Institute]. Bundesgesundheitsblatt, Gesundheitsforschung, Gesundheitsschutz 55 (6-7), 836-842. https://doi.org/10. 1007/s00103-012-1486-3.
Kamtsiuris, P./Lange, M./Schaffrath Rosario, A. (2007). Der Kinder- und Jugendgesundheitssurvey (KiGGS): Stichprobendesign, Response und Nonresponse-Analyse. Bundesgesundheitsblatt, Gesundheitsforschung, Gesundheitsschutz 50 (5-6), 547-556. https://doi.org/10. 1007/s00103-007-0215-9.

Kromeyer-Hauschild, K./Wabitsch, M./Kunze, D./Geller, F./Geiß, H. C./Hesse, V./Hippel, A. von/Jaeger, U./Johnsen, D./Korte, W./Menner, K./Müller, G./Müller, J. M./Niemann-Pilatus, A./Remer, T./Schaefer, F./Wittchen, H.-U./Zabransky, S./Zellner, K./Ziegler, A./Hebebrand, J. (2001). Perzentile für den Bodymass-Index für das Kindes- und Jugendalter unter Heranziehung verschiedener deutscher Stichproben. Monatsschrift Kinderheilkunde 149 (8), 807-818. https://doi.org/10.1007/s001120170107.

La Guzmán-de Garza, F. J./González Ayala, A. E./Gómez Nava, M./Martínez Monsiváis, L. I./Salinas Martínez, A. M./Ramírez López, E./Mathiew Quirós, A./Garcia Quintanilla, F. (2017). Body frame size in school children is related to the amount of adipose tissue in different depots but not to adipose distribution. American Journal of Human Biology 29 (5). https://doi.org/10.1002/ajhb.23014.

Lorenzo, A. de/Martinoli, R./Vaia, F./Di Renzo, L. (2006). Normal weight obese (NWO) women: an evaluation of a candidate new syndrome. Nutrition, Metabolism, and Cardiovascular Diseases 16 (8), 513-523. https://doi.org/10.1016/j.numecd.2005.10.010.

Marques-Vidal, P./Pécoud, A./Hayoz, D./Paccaud, F./Mooser, V./Waeber, G./Vollenweider, P. (2010). Normal weight obesity: relationship with lipids, glycaemic status, liver enzymes and inflammation. Nutrition, Metabolism, and Cardiovascular Diseases 20 (9), 669-675. https://doi.org/10.1016/j.numecd.2009.06.001.

Mokhtar, N./Elati, J./Chabir, R./Bour, A./Elkari, K./Schlossman, N. P./Caballero, B./Aguenaou, H. (2001). Diet culture and obesity in northern Africa. The Journal of Nutrition 131 (3), 887S-892S. https://doi.org/10.1093/jn/131.3.887S.

Mumm, R. (2015). It's a matter of tempo - influence of the individual developmental tempo in adolescents on anthropometric measures and growth references [Eine Frage des Tempos - Der Einfluss der indivuellen Entwicklungsgeschwindigkeit von Jugendlichen auf anthropometrische Maße und Wachstumsreferenzen]. Master thesis. Potsdam, University of Potsdam.

Mumm, R./Godina, E./Koziel, S./Musalek, M./Sedlak, P./Wittwer-Backofen, U./Hesse, V./Dasgupta, P./Henneberg, M./Scheffler, C. (2018). External skeletal robusticity of children and adolescents - European references from birth to adulthood and international comparisons. Anthropologischer Anzeiger 74 (5), 383-391. https://doi.org/10.1127/anthranz/2018/0826. 
Musálek, M./Pařízková, J./Godina, E./Bondareva, E./Kokštejn, J./Jírovec, J/Vokounová, Š. (2018). Poor skeletal robustness on lower extremities and weak lean mass development on upper arm and calf: normal weight obesity in middle-school-aged children (9 to 12). Frontiers in Pediatrics 6, 371. https://doi.org/10.3389/fped.2018.00371.

Navazo, B./Oyhenart, E./Dahinten, S./Mumm, R./Scheffler, C. (2020). Decrease of external skeletal robustness (Frame Index) between two cohorts of school children living in Puerto Madryn, Argentina at the beginning of the 21st century. Anthropologischer Anzeiger 77 (5), 405-413. https://doi.org/10.1127/anthranz/2020/1182.

NCD Risk Factor Collaboration (2017). Worldwide trends in body-mass index, underweight, overweight, and obesity from 1975 to 2016: a pooled analysis of 2416 population-based measurement studies in 128.9 million children, adolescents, and adults. The Lancet 390 (10113), 2627-2642. https://doi.org/10.1016/S01406736(17)32129-3.

Nickerson, B. S./Esco, M. R./Fedewa, M. V./Park, K.S. (2020). Development of a body mass index-based body fat equation: effect of handgrip strength. Medicine and Science in Sports and Exercise 52 (11), 2459-2465. https://doi.org/10.1249/MSS.0000000000002383.

Plachta-Danielzik, S./Gehrke, M. I./Kehden, B./Kromeyer-Hauschild, K./Grillenberger, M./Willhöft, C./Bosy-Westphal, A./Müller, M. J. (2012). Body fat percentiles for German children and adolescents. Obesity Facts 5 (1), 77-90. https://doi.org/10.1159/000336780.

Pomeroy, E./Macintosh, A./Wells, J. C. K./Cole, T. J./Stock, J. T. (2018). Relationship between body mass, lean mass, fat mass, and limb bone cross-sectional geometry: implications for estimating body mass and physique from the skeleton. American Journal of Physical Anthropology 166 (1), 56-69. https://doi.org/10.1002/ajpa.23398.

Prentice, A. M./Jebb, S. A. (2001). Beyond body mass index. Obesity Reviews 2 (3), 141-147. https://doi.org/10. 1046/j.1467-789x.2001.00031.x.

Preuschoft, H. (2004). Mechanisms for the acquisition of habitual bipedality: are there biomechanical reasons for the acquisition of upright bipedal posture? Journal of Anatomy 204 (5), 363-384. https://doi.org/10.1111/j. 0021-8782.2004.00303.x.

Rietsch, K./Eccard, J. A./Scheffler, C. (2013a). Decreased external skeletal robustness due to reduced physical activity? American Journal of Human Biology 25 (3), 404-410. https://doi.org/10.1002/ajhb.22389.

Rietsch, K./Godina, E./Scheffler, C. (2013b). Decreased external skeletal robustness in schoolchildrena global trend? Ten year comparison of Russian and German data. PloS One 8 (7), e68195. https://doi.org/10.1371/journal.pone.0068195.
Romero-Corral, A./Somers, V. K./Sierra-Johnson, J./Korenfeld, Y./Boarin, S./Korinek, J./Jensen, M. D./Parati, G./Lopez-Jimenez, F. (2010). Normal weight obesity: a risk factor for cardiometabolic dysregulation and cardiovascular mortality. European Heart Journal 31 (6), 737-746. https://doi.org/10.1093/eurheartj/ehp487.

Schaffrath, Rosario A./Kurth, B.-M./Stolzenberg, H./Ellert, U./Neuhauser, H. (2010). Body mass index percentiles for children and adolescents in Germany based on a nationally representative sample (KiGGS 2003-2006). European Journal of Clinical Nutrition 64 (4), 341-349. https://doi.org/10.1038/ejcn.2010.8.

Scheffler, C. (2010). The change of skeletal robustness of 6-12 years old children in Brandenburg (Germany)-comparison of body composition 1999-2009. Anthropologischer Anzeiger 68 (2), 153-165. https://doi. org/10.1127/0003-5548/2011/0095.

Scheffler, C./Hermanussen, M. (2014). Is there an influence of modern life style on skeletal build? American Journal of Human Biology 26 (5), 590-597. https://doi.org/10.1002/ajhb.22561.

Scheffler, C./Hermanussen, M. (2018). Growth in childhood and adolescence. In: W. Trevathan (Ed.). The international encyclopedia of biological anthropology. Hoboken, NJ, Wiley Blackwell, 693-703.

Schilitz, A. (2001). Körperliche Entwicklung und Körperzusammensetzung von Brandenburger Schulkindern im Geschlechter- und Altersgruppenvergleich. Zugl.: Potsdam, Univ., Diss, 2001. Aachen, Shaker.

Schüler, G. (2009). Potsdamer Längsschnittstudie: Beurteilung der körperlichen Entwicklung vom Kleinkindalter bis zum frühen Schulalter mit Hilfe von Somatometrie, Fotogrammetrie und Morphognose. Dissertation. Potsdam, University of Potsdam.

Schwandt, P./Eckardstein, A: von/Haas, G.-M. (2012). Percentiles of percentage body fat in german children and adolescents: an international comparison. International Journal of Preventive Medicine 3 (12), 846-852.

Slaughter, M. H./Lohman, T. G./Boileau, R. A./Horswill, C. A./Stillman, R. J./van Loan, M. D./Bemben, D. A. (1988). Skinfold equations for estimation of body fatness in children and youth. Human biology 60 (5), 709-723.

Swinburn, B. A./Kraak, V. I./Allender, S./Atkins, V. J./Baker, P. I./Bogard, J. R./Brinsden, H./Calvillo, A./Schutter, O. de/Devarajan, R./Ezzati, M./Friel, S./Goenka, S./Hammond, R. A./Hastings, G./Hawkes, C./Herrero, M./Hovmand, P. S./Howden, M./Jaacks, L. M./Kapetanaki, A. B./Kasman, M./Kuhnlein, H. V./Kumanyika, S. K./Larijani, B./Lobstein, T./Long, M. W./Matsudo, V. K. R./Mills, S. D. H./Morgan, G./Morshed, A./Nece, P. M./Pan, A./Patterson, D. W./Sacks, G./Shekar, M./Simmons, G. L./Smit, W./Tootee, A./Vandevijvere, S./Waterlander, W. E./Wolfenden, L./Dietz, W. H. (2019). The Global Syndemic of Obesity, Undernutrition, and Climate Change: The Lancet Commission report. The Lancet 393 (10173), 791-846. https://doi.org/ 10.1016/S0140-6736(18)32822-8. 
Tanner, J. M. (1962). Growth at adolescence. With a general consideration af the effects of hereditary and environmental factors upon growth and maturation from birth to maturity. 2nd ed. Oxford, Blackwell Scientific Publications.

Ulijaszek, S. J./Lourie, J. A. (1994). Intra- and inter-observer error in anthropometric measurement. In: C. G. N. Mascie-Taylor/S. J. Ulijaszek (Eds.). Anthropometry. The individual and the population. Cambridge, Cambridge University Press, 30-55.

Wells, J. C. K. (2014). Toward body composition reference data for infants, children, and adolescents. Advances in Nutrition 5 (3), 320S-329S. https://doi.org/10.3945/an.113.005371.

Wells, J. C. K. (2018). Body composition. In: W. Trevathan (Ed.). The international encyclopedia of biological anthropology. Hoboken, NJ, Wiley Blackwell, 1-8.
Wickramasinghe, V. P. (2012). Hattori chart based evaluation of body composition and its relation to body mass index in a group of Sri Lankan children. Indian Journal of Pediatrics 79 (5), 632-639. https://doi.org/10.1007/ s12098-011-0615-6.

Wohlfahrt-Veje, C./Tinggaard, J./Winther, K./Mouritsen, A./Hagen, C. P./Mieritz, M. G./Renzy-Martin, K. T. de/Boas, M./Petersen, J. H./Main, K. M. (2014). Body fat throughout childhood in 2647 healthy Danish children: agreement of BMI, waist circumference, skinfolds with dual X-ray absorptiometry. European Journal of Clinical Nutrition 68 (6), 664-670. https://doi.org/10.1038/ejcn.2013.282.

Woolcott, O. O./Bergman, R. N. (2019). Relative fat mass as an estimator of whole-body fat percentage among children and adolescents: a cross-sectional study using NHANES. Scientific Reports 9 (1), 15279. https://doi org/10.1038/s41598-019-51701-z. 